Reciprocal Relations of Subjective Sleep Quality and Affective Well-Being in Late Childhood

Andreas B. Neubauer ${ }^{1,2}$, Andrea C. Kramer ${ }^{1,2}$, Andrea Schmidt ${ }^{1,2}$, Tanja Könen ${ }^{2,3}$, Judith Dirk ${ }^{1,2}, \&$ Florian Schmiedek ${ }^{1,2,4}$

${ }^{1}$ DIPF | Leibniz Institute for Research and Information in Education, Frankfurt a. M.,

Germany

${ }^{2}$ Center for Research on Individual Development and Adaptive Education of Children at Risk (IDeA), Frankfurt a. M., Germany

${ }^{3}$ Department of Psychology, University of Koblenz-Landau, Landau, Germany

${ }^{4}$ Goethe-University, Frankfurt a. M., Germany

Author note: Study 1 was funded by the German Research Foundation (DFG;

Deutsche Forschungsgemeinschaft; Grant SCHM 2411/9-1). Study 2 was funded by the Jacobs Foundation (grant number 2016-1245-00).

Correspondence concerning this article should be addressed to Andreas B. Neubauer, DIPF | Leibniz Institute for Research and Information in Education, and Center for Research on Individual Development and Adaptive Education of Children at Risk (IDeA), Rostocker Straße 6, 60323 Frankfurt a. M., Germany. E-mail: neubauer.andreas@dipf.de

This paper has been accepted for publication in Developmental Psychology.

(C) 2021, American Psychological Association. This paper is not the copy of record and may not exactly replicate the final, authoritative version of the article. 


\begin{abstract}
High sleep quality has been associated with beneficial outcomes across the lifespan. Intensive longitudinal studies suggest that these beneficial effects can also be observed on a day-to-day level. However, the dynamic interplay between subjective sleep quality and affective wellbeing in children's daily life has only rarely been investigated. The aims of the present work were (a) to replicate findings from a prior ambulatory assessment study in this area (Könen et al., 2016), (b) to explore the effect of subjective sleep quality on well-being throughout the day, and (c) to examine the reciprocal relation between subjective sleep quality and wellbeing in more detail. Data from two ambulatory assessment studies with children between 8 and 11 years $(\mathrm{N}=108 / 84$, with assessments over 28 / 21 consecutive days $)$ consistently showed that positive affect was higher and negative affect was lower after nights with better sleep quality, and that the effects of subjective sleep quality were stronger on well-being assessed in the morning compared to later in the day. Results from dynamic structural equation models revealed reciprocal effects of subjective sleep quality and positive affect. Negative affect was not consistently related to worse subsequent sleep quality after controlling for positive affect and prior night's sleep quality. Results suggest a close relation of sleep quality and positive affect, which strengthens the idea behind interventions targeting both, children's sleep and well-being. Differences between children in the dynamic interplay between sleep and affect may be important predictors of long-term outcomes.
\end{abstract}

Keywords: well-being; sleep; ambulatory assessment; dynamic structural equation modeling 


\section{Reciprocal Relations of Subjective Sleep Quality and Affective Well-Being in Late}

\section{Childhood}

Accumulating evidence has reported links of subjective sleep quality with affective well-being. For instance, more positive and less negative affective states have been associated with more optimal sleep in adolescence (Fuligni \& Hardway, 2006; van Zundert et al., 2015) as well as in young and old adulthood (Ong et al., 2017; Peltz et al., 2016; Steptoe et al., 2008; Wild-Hartmann et al., 2013). Still missing from the extant literature is, however, a nuanced understanding of the interplay of sleep quality and well-being in late childhood. Given the well-established effects of pubertal development on sleep (Campbell \& Feinberg, 2009; Carskadon et al., 1993; Fredriksen et al., 2004; Kurth et al., 2010), better understanding the dynamics among sleep quality and well-being before the start of puberty (i.e., in late childhood) is needed: Sleep deficits in children and adolescents have been identified as a threat to mental health and academic engagement (Curcio et al., 2006; Fredriksen et al., 2004; Kalak et al., 2014; Paavonen et al., 2003; Paruthi et al., 2016). Research on the association of sleep quality and well-being before the "storm" of puberty might therefore aid in identifying adaptive patterns and developing interventions to uphold healthy sleep behavior. The central aim of this work therefore was to illuminate the dynamic interplay between subjective sleep quality and affective well-being in late childhood.

\section{Sleep Quality and Affect: A Reciprocal Association?}

Reviews generally emphasize the relation of sleep and affect as reciprocal (Deliens et al., 2014; Kahn et al., 2013). Measurement-intensive studies (i.e., studies with several repeated assessments per participant collected over several days or weeks) are particularly suitable to investigate reciprocal relations in daily life. For example, data by Peltz et al. (2016) suggest a reciprocal relation between subjective sleep quality and anxiety in young adults, whereas such reciprocal effects have been reported for positive affect (but not negative affect) in a study by Wild-Hartmann et al. (2013). To integrate these various findings, a recent review 
summarized the results of studies that have examined sleep and mood on a daily level (Konjarski et al., 2018). Findings from this review suggest that subjective sleep quality is rather consistently associated with subsequent positive and negative affect, whereas evidence for the reverse effect (daily well-being and subsequent sleep quality) is more equivocal. More specifically, in 15 studies (out of 17) included in this review, better subjective sleep quality was associated with higher positive affect on the following day. Similarly, 13 studies (out of 15) reported a negative prospective association of subjective sleep quality with negative affect. In contrast, the reverse effect (better sleep quality in nights after days with higher positive and lower negative affect) was reported in 8 out of 12 studies (for positive affect) and 5 out of 13 studies (for negative affect) only.

\section{Sleep and Affect in Late Childhood}

Previous research suggests that sleep plays an important role for affect and mental health in late childhood (Astill et al., 2012). Findings reported by El-Sheikh et al. (2019) show that in a sample of 282 children, child-reported sleep problems were associated with internalizing problems (reported by the mother) in a U-shaped fashion. Subjective sleep quality in children (8-10 years) also predicted internalizing problems 2-3 years later in a longitudinal study by Kelly and El-Sheikh (2014). However, only a handful of studies thus far has examined the day-to-day associations among sleep and positive and negative affect in children. As a case in point, of the 29 studies included in the systematic review by Konjarski et al. (2018), only four included children of 12 years or younger. For example, Kouros and ElSheikh (2015) report data showing that actigraphy-based indicators of sleep duration and parent-reported sleep quality of 142 children did not predict affect the next day on the withinperson level, but daily affect predicted subsequent nightly sleep quality (i.e., sleep fragmentation and latency). Research using ambulatory assessment (Trull \& Ebner-Priemer, 2013) to capture specifically the dynamic interplay of subjective sleep quality with well-being in late childhood is, however, scarce. Specifically, the review by Konjarski et al. (2018) 
identified only one such study: Findings from this ambulatory assessment study (Könen et al., 2016) with four daily assessments conducted over four consecutive weeks showed that children's self-reported sleep quality (but not self-reported time in bed) predicted both selfreported positive affect and negative affect on the next day. Only positive affect but not negative affect was associated with better subsequent nightly sleep quality. While these findings are in line with the results reported in the literature on adolescents and adults, they require replication in independent samples before more definite conclusions can be drawn. One central aim of this work was therefore to replicate the results reported in Könen et al. (2016).

\section{The Present Work}

Pre-registered Conceptual Replication of Könen et al. (2016). The first central aim of this work was a conceptual replication of the central findings reported in the ambulatory assessment study by Könen et al. (2016). Specifically, Könen et al. (2016) reported that subjective sleep quality was associated with higher positive affect assessed in the morning, in the late morning, and in the afternoon. Subjective sleep quality was associated with lower negative affect assessed in the morning and late morning (but not in the afternoon). When it comes to the reverse association (affect predicting subsequent sleep quality), positive but not negative affect assessed in the evening (prior to going to bed) emerged as a meaningful predictor in the study by Könen et al. (2016). Building on these findings, we pre-registered ${ }^{1}$ the following hypotheses:

Hypothesis 1: Subjective sleep quality (but not child-reported time in bed) predicts affective well-being the next day. Specifically, we expected an association of sleep quality with positive affect on all assessments on the next day (morning, late morning, afternoon,

\footnotetext{
${ }^{1}$ Please note that the pre-registered hypotheses of this work can be found in two separate pre-registrations (Hypothesis 1: https://osf.io/kmgtu/?view only=be06e93b6ba64a9a858b80f617e2bba2; Hypotheses 2a - 2c: https://osf.io/9dx67/?view_only=546aaa62b3a247ddb53193e64b7acd09). The first pre-registration contains additional hypotheses that will not be tested in this work, but will be reported in a separate manuscript. The second pre-registration contains only hypotheses reported in this work.
} 
evening). For negative affect, we predicted only an association with the early assessments (morning, late morning) but not the late assessments (afternoon, evening). We also predicted that there would be meaningful inter-individual differences in the size of the effect of sleep quality on affect.

Hypothesis 2a: Negative affect assessed in the evening does not predict subsequent subjective sleep quality.

In addition to this conceptual replication, we extended prior work in three ways.

Extension 1: Time of Day. We examined if the association between subjective sleep quality and affective well-being differs depending on the time of day when affective states are assessed. While this research question was largely exploratory, it seems plausible to expect that the effects of sleep on well-being diminish throughout the day (see e.g., Murray et al., 2002, for within-day changes in affect). A study by Cox et al. (2018) showed that the association between total sleep time and anxiety on the next day in a sample of adults decreased throughout the day: the effect was strongest for anxiety assessed in the morning, weaker for afternoon anxiety, and no longer statistically meaningful for evening anxiety. In a similar vein, the effect of last night's self-reported sleep quality on today's negative affect in children (Könen et al., 2016) was only statistically significant for negative affect in the morning and late morning, but not in the afternoon. In contrast, subjective sleep quality was associated with positive affect in the morning, late morning, and afternoon in that study. Therefore, we examined the role of assessment time for the relation between subjective sleep quality and subsequent affective well-being: We explored if the time point at which wellbeing is assessed (in the morning, late morning, afternoon, or evening) modulates the association of last night's subjective sleep quality with well-being.

Findings by Könen et al. (2016) further showed that negative affect assessed in the evening did not predict sleep quality the following night. While this is generally in line with the findings summarized by Konjarski et al. (2018) regarding somewhat inconsistent effects 
of negative affect on subsequent sleep quality, it might also be that while negative affect assessed directly prior to bedtime is unrelated to sleep quality, average negative affect throughout the day is a better predictor for sleep quality. Conceptually, accumulating negative experiences might have consequences beyond single negative experiences, as shown in the domain of stressor accumulation, which predicts negative affective states above and beyond the occurrence of single stressors (Schilling \& Diehl, 2014). Furthermore, from a psychometric perspective, averaging negative affect from multiple assessments of the day yields a more reliable estimate, which might, in turn, increase validity of the assessment and / or statistical power. However, given the prevailing evidence of rather weak links between negative affect and subsequent sleep quality, we tentatively predicted that average negative affect throughout the day would be unrelated to subsequent subjective sleep quality.

Hypothesis 2b: Average daily negative affect is unrelated to subsequent subjective sleep quality.

Extension 2: Subfacets of Negative Affect. Another possible explanation for the inconsistent effects of negative affect on sleep quality might be that different types of negative affective states vary in their impact on sleep quality. Potentially, high arousal negative affect is more closely linked to subsequent sleep quality than low arousal negative affect, because arousal and sleep are opponent processes (Szymusiak \& McGinty, 2008). In fact, a study on adolescents showed that while low arousal positive and negative affect are associated with better subsequent objective sleep parameters (assessed via actigraphy), high arousal positive and negative affect decreased sleep quality in the following night (Tavernier et al., 2016). Similarly, worries - perseverative cognitions linked to a higher arousal component of negative affective states - have been associated to poor sleep quality as well (Weise et al., 2013). We therefore tested if a more arousing negative affective state - specifically: tense arousal, which has recently been linked to worries in children (Kramer et al., 2020) - would predict subsequent sleep quality in children's daily lives. 
Hypothesis 2c: Tense arousal is hypothesized to predict subjective sleep quality in the following night. We expect that both tense arousal assessed in the evening, and average tense arousal assessed throughout the day are associated with subsequent subjective sleep quality.

Extension 3: Reciprocal Effects. To examine the potential reciprocal associations between subjective sleep quality and affective well-being, we used dynamic structural equation modeling (DSEM). DSEM combines elements of multilevel models, time series analyses, and structural equation models. A central advantage of this approach is that it allows to examine reciprocal within-person lead-lag associations among multiple variables simultaneously (Asparouhov et al., 2017). We used DSEM to examine potential reciprocal effects between subjective sleep quality and affective well-being in children's daily lives.

Summary. The aims of the present work were (1) to conceptually replicate earlier work by Könen et al. (2016), and extend this work in several ways by (2) exploring the role of time of day of the assessment of affective well-being, (3) targeting potential differences between negative affect facets, and (4) approaching the postulated reciprocal relation between subjective sleep quality and affective well-being using DSEM. We approached our research aims with two independent ambulatory assessment studies. Hypotheses 1 through $2 \mathrm{c}$ and the data analysis plan to test the hypotheses were pre-registered on the Open Science Framework before the start of data collection of Study 1. Study 2 was conducted as an attempt to replicate findings from Study 1 and to test the robustness of our results in an independent sample. Data and analysis code for both studies can be retrieved from the accompanying OSF repository (https://osf.io/an5bk/?view_only=15d86e7adab548afb31484bdf86e8984).

\section{Study 1}

\section{Method}


Participants. One-hundred and eight fifth graders (44.4\% boys) between the ages 9 to $11(M=10.11$ years, $S D=0.44)$ participated in this study ${ }^{2}$. According to the Pubertal Development Scale (Petersen et al., 1988; Watzlawik, 2009), participating children were classified as prepubertal (15 boys, 10 girls), early pubertal (21 boys, 10 girls), or midpubertal (1 boy, 17 girls). No child was classified as late pubertal and postpubertal; 34 children did not provide responses on this scale and could, hence, not be classified. In the families of 74 children (68.5\%), German was either the only language spoken at home or the primary language spoken. Children's parents were mostly employed either in full-time (101 fathers and 17 mothers) or part-time (4 fathers, 69 mothers). Most children (104; 96.3\%) were born in Germany.

Procedure. Data of this study was collected within the [blinded] project, which comprised two intensive measurement bursts and a follow-up assessment. Prior work using data from this project have targeted the association between XX and YY [blinded] and between XX and YY [blinded]. Thus far, no other work has utilized information on children's sleep collected in this project. The study was planned as a longitudinal investigation of school transition challenges, with the same children participating in all three assessments. However, due to logistic reasons and one school cancelling participation on a short notice, there were only four children participating longitudinally (for more information, see study protocol: [blinded]). In the current work, the ambulatory assessment data of the second measurement burst is presented as was specified in the pre-registration.

Research assistants presented the study in all six participating classes and distributed written project information. Parents and children could voluntarily register for participation by

\footnotetext{
${ }^{2}$ Sample size for this study and Study 2 were not determined specifically for this research purpose. However, we conducted an a-priori power analysis for sample size in Study 2 for a similar research question (a small withinperson association between two variables with the predictor uniquely accounting for $1 \%$ of the within-person variance of the outcome). This power analysis yielded adequate power of $97.6 \%$. Since both the sample size (108) and the number of repeated observations (28) were even larger in Study 1, we deemed the design adequately powered to detect a small within-person effect.
} 
providing written informed consent. The measurement burst consisted of a 4-week period of intensive data collection in children's daily lives, embedded within pre- and posttests at which children were instructed how to respond to the items on research smartphones, and provided background and trait data. During the four school weeks of ambulatory assessment, there were four assessments each day. The assessments were prompted on the same time of the day each day throughout the study and children were given a time window during which the survey could be completed: in the mornings (6:00-7:50 am), in the late mornings (9:50 am), in the afternoons (3:00-5:15 pm or 4:00-5:45 pm on longer school days), and in the evenings (6:308:30 pm). The late morning session took place while children were at school; the other measures were taken outside the class context. Children received gift certificates of $25 €$ as remuneration for participation. They could earn bonus gift certificates of additional $5 €$ if they completed at least $60 \%$ of all assessments, and additional $10 €$ for $85 \%$ completed assessments. Compliance rates were satisfactory and ranged from $71.0 \%$ (afternoon session) to $80.6 \%$ (late morning session) of completed assessments. The study was approved by the ethics committee of the German Psychological Society (DGPs).

\section{Measurements.}

Momentary affect and tense arousal. State affect was assessed at all four measurement occasions of the day. Participants were asked to rate seven items about their current affect. All of these items started with the stem sentence "Right now, I feel...", which was followed by three items asking for positive affect (good; fantastic; content), three items asking for negative affect (unhappy; miserable; afraid), and one item inquiring about current tense arousal (uneasy). All items were answered on a five-point Likert scale ranging from "not at all true" (coded as 1) to "completely true" (coded as 5). At all four measurement occasions, the three negative affect items and the three positive affect items were averaged. Positive and negative affect items were the same as used by Könen et al. (2016). Daily affect was obtained as the mean of the four daily ratings. Reliability was estimated using multilevel 
McDonald's $\omega$ (Geldhof et al., 2014) for momentary measures nested within participants. The resulting internal consistency estimates for the four measurement occasions were $\omega=.76 / .77$ $/ .76 / .79$ (positive affect within), $\omega=.79 / .76 / .80 / .80$ (negative affect within), $\omega=.97$ (positive affect between), and $\omega=.99$ (negative affect between). The observed range of within-person reliabilities largely overlaps with related findings on adults (Brans et al., 2013; Wilhelm \& Schoebi, 2007). Children aged 8 to 11 years can report their affective states in a differentiated way (Leonhardt et al., 2016; Walden et al., 2003).

Sleep quality. Subjective sleep quality was assessed in the morning questionnaire using three items. All items were answered on a 5-point Likert scale: (1) "How well did you sleep last night?” (1 = “very poorly" to 5 = “very well”); (2) "How restlessly did you sleep last night?" (1 = "not at all" to 5 = "very"); (3) "How easily did you fall asleep yesterday evening?" ( 1 = "very hard" to 5 = "very easily"). These are the same items as used in Könen et al. (2016), which were based on the sleep quality index by Åkerstedt et al. (2012). The three items were averaged into one measure of sleep quality per person and night (after item 2 had been inverted). Internal consistency was $\omega=.59$ on the within-person level and $\omega=.89$ on the between-person level, which is in line with the original publication (Könen et al., 2016). Children aged 8 to 11 years have one single nighttime sleep period per day (regular daytime napping usually stops at 5 or 6 years; Hill et al., 2007) and are able to report on their sleep (Meltzer et al., 2012; Schwerdtle et al., 2010).

Time in bed. As indicator of subjective sleep duration, time in bed is the duration between going to bed and waking up (which is closely related but slightly longer than the actual amount of time asleep; Meijer et al., 2010). Every morning, participants were asked to indicate when they went to bed last night and when they woke up today. They responded by choosing the hour and the minutes (in ten minute intervals) for both time points. As stated in our pre-registration, we checked for nonsensical responses in the following way: If the selfreported wake up time was later than the time point at which they filled in the morning 
questionnaire (= the time stamp provided by the app), wake up time was set to missing (278 of 2,213 provided wake up times were set to missing following this procedure). Similarly, if the self-reported bed time was before the time point at which they filled in the last questionnaire of the previous day, bed time was set to missing (178 of 2,207 provided bed times were set to missing following this procedure). Time in bed was computed as the difference between wake up time and bed time. Negative sleep duration estimates $(n=10)$ were set to missing values.

Data analysis. We used multilevel models to account for the nested data structure of our data (with daily measures on Level 1 nested within individuals on Level 2).

Predicting affect. Child $j$ 's affect on day $d$ was entered as dependent variable $\left(N A_{d j}\right.$ or $P A_{d j}$ ). We ran separate models for affect assessed at the morning session (Models 1a and 1b), late morning session (Models 2a and 2b), afternoon session (Models 3a and 3b), and evening session (Models 4a and 4b). In all models, the following predictors were included: study day (day $_{d j}$; the first day was coded as 0 ); school day ( school $_{d j}$; school days were coded as 1 , weekend days as 0$)$; sleep quality $\left(\mathrm{sq}_{d j}\right)$; time in bed $\left(\mathrm{tib}_{d j}\right)$, as well as person means of sleep quality (sq. $\operatorname{pmean}_{j}$ ) and time in bed (tib. $\operatorname{pmean}_{j}$ ). Sleep quality and time in bed were centered on their respective person means; the person means of sleep quality and time in bed were centered on their grand means. Hence, the respective effects are pure estimates of within-person effects and between-person effects, respectively (Wang \& Maxwell, 2015). Random effects were estimated for the effects of study day and sleep quality, and covariances among random effects were freely estimated.

The formal description of the final model for a model predicting negative affect is: Level 1:

$$
N A_{d j}=\beta_{0 j}+\beta_{1 j} \cdot \operatorname{day}_{d j}+\beta_{2} \cdot \operatorname{school}_{d j}+\beta_{3 j} \cdot \mathrm{sq}_{d j}+\beta_{4} \cdot \operatorname{tib}_{d j}+\varepsilon_{d j}
$$

Level 2:

$$
\beta_{0 j}=\gamma_{00}+\gamma_{01} \cdot \text { sq. } \text { pmean }_{j}+\gamma_{02} \cdot \text { tib. } \text { pmean }_{j}+v_{0 j}
$$




$$
\begin{aligned}
& \beta_{1 j}=\gamma_{10}+v_{1 j} \\
& \beta_{3 j}=\gamma_{30}+v_{3 j}
\end{aligned}
$$

Predicting sleep quality. In the next set of models, sleep quality was the dependent variable. It was predicted by either negative affect in the evening assessment of the previous day $\left(N A e_{(d-1) j}\right.$; Model 5a), mean negative affect of the whole previous day $\left(N A d_{(d-1) j}\right.$; Model 5b), tense arousal in the evening assessment of the previous day $\left(t A e_{(d-1) j}\right.$; Model 6a), or mean tense arousal of the whole previous day $\left(t A d_{(d-1) j} ;\right.$ Model 6b). In all models, study day and school day were included as timevarying predictors. Furthermore, the person means of all negative affect assessments (Models $5 \mathrm{a}$ and $5 \mathrm{~b}$ ) or of all tense arousal assessments (Models $6 \mathrm{a}$ and $6 \mathrm{~b}$ ) were included as predictors. Negative affect ratings and tense arousal ratings were person-mean centered, the person means were grand-mean centered prior to the analyses. Random effects were estimated for the effects of study day, school day, and negative affect / tense arousal, and covariances among random effects were freely estimated. For Model 5a, the formal description is:

Level 1:

$$
S Q_{d j}=\beta_{0 j}+\beta_{1 j} \cdot \operatorname{day}_{d j}+\beta_{2 j} \cdot \operatorname{school}_{d j}+\beta_{3 j} \cdot N A e_{(d-1) j}+\varepsilon_{d j}
$$

Level 2:

$$
\begin{aligned}
& \beta_{0 j}=\gamma_{00}+\gamma_{01} \cdot \text { NA. pmean } \text { pmo }_{j}+v_{0 j} \\
& \beta_{1 j}=\gamma_{10}+v_{1 j} \\
& \beta_{2 j}=\gamma_{20}+v_{2 j} \\
& \beta_{3 j}=\gamma_{30}+v_{3 j}
\end{aligned}
$$

As pre-registered, we examined if the effects remained robust in the following sensitivity analyses: (a) when excluding children who had already participated at Burst $1(N=$ 4), (b) when removing fixed and random time trends, and (c) when removing the most extreme $(2.5 \%$ lowest and $2.5 \%$ highest $)$ time in bed estimates. We conducted additional 
(non-preregistered) sensitivity analyses in which we (d) controlled for children's age and gender, or (e) replaced nonsensical estimates for time of going to bed and waking up, respectively, with the time stamp provided by the app (instead of setting these values to missing). Models were estimated using the nlme package in R (Pinheiro et al., 2019) using restricted maximum likelihood estimation. Descriptive statistics of the study variables (see Table 1) were obtained via a multilevel structural equation model in Mplus version 8.3. Following our pre-registration, an $\alpha$-level of .05 (two-tailed, no explicit correction for multiple testing) was employed for all analyses.

\section{Results and Discussion}

\section{Predicting affect.}

Pre-registered analyses. Table 2 depicts results for Models 1 through 4. Higher than usual sleep quality was associated with higher positive affect in the morning session, $b=.250$, $p<.001$, in the late morning session, $b=.131, p<.001$, and in the evening session, $b=.093$, $p=.006$. Contrary to our expectations, the within-person effect of sleep quality on positive affect in the afternoon session was not statistically meaningful, $b=.067, p=.105$. For negative affect, there was a significant negative association with sleep quality in the morning session, $b=-.241, p<.001$, and in the afternoon session, $b=-.105, p=.021$, but not in the late morning session, $b=-.119, p=.062$, or evening session, $b=-.131, p=.056$. Time in bed was only associated with negative affect in the afternoon, with longer time in bed associated with slightly higher afternoon negative affect, $b=.046, p=.044$. In all other models, the within-person effect of time in bed was not statistically significant, $p>.076$. Hence, our first research hypothesis was only partially confirmed.

In all sensitivity analyses (see Online Supplement Tables S1 to S5), all statistically significant effects of sleep quality remained significant. In addition, higher sleep quality was associated with lower negative affect in the late morning when removing the fixed and random effect of study day, or when cases with extreme time in bed estimates were removed. 
Higher sleep quality was associated with lower subsequent evening negative affect in the models when the fixed and random effect of study day were removed, or when nonsensical time-in-bed estimates were replaced by app based time stamps. Finally, when removing the fixed and random effect of study day, the positive effect of sleep quality with afternoon positive affect was also statistically significant.

We next examined whether there were meaningful inter-individual differences in the within-person association of sleep quality and momentary affect. To that end, we ran the same eight models, but this time excluded the random effect of sleep quality. Model fit deteriorated for the Models 1a, 1b, 2a, and 3b. Hence, only for the models predicting positive affect in the morning session, $\chi^{2}(3)=54.84, p<.001$, positive affect in the late morning session, $\chi^{2}(3)=$ $8.21, p=.042$, negative affect in the morning session, $\chi^{2}(3)=27.82, p<.001$, and negative affect in the afternoon session, $\chi^{2}(3)=10.14, p=.017$, there was evidence for meaningful inter-individual differences in the within-person effect of sleep quality on affective wellbeing. In the other four models, removing the random effect of sleep quality did not deteriorate model fit, $\chi^{2}(3)<7.22, p>.065$.

Hence, the hypothesized positive effect of sleep quality on positive affect was observed for positive affect in the morning, late morning, and evening session, but not for positive affect in the afternoon session. Taken together, these results provide rather robust evidence for the postulated association between sleep quality and subsequent positive affect. As predicted, sleep quality was related to lower negative affect in the morning session and unrelated to negative affect in the following evening. However, contrary to expectations, sleep quality predicted negative affect in the afternoon, but not in the late morning session. We also hypothesized that there would be meaningful inter-individual differences in the within-person association of sleep quality and affective well-being. Findings revealed inconsistent results, with statistically meaningful random effects in only four (out of eight) models. 
Exploratory analyses. Results suggest that the effect of sleep quality on affective wellbeing becomes weaker throughout the day. To test whether the change in the effect of sleep quality on affective well-being is statistically meaningful, we set up a three-level model with four assessments per day (Level 1) nested within days (Level 2) nested within children (Level 3). Time of day (morning, late morning, afternoon, evening) was entered as a factor with Helmert contrasts (i.e., comparing morning against the three later assessments, late morning against the two later assessments, and afternoon against evening assessment). We also entered the interaction between time of day and time-varying sleep quality in the model. Results showed that the association between sleep quality and both positive affect, $b=.108, p<.001$, and negative affect, $b=-.115, p<.001$, was stronger for affect assessed in the morning (i.e., contemporaneously to sleep quality) than for affect assessed later in the day. The association between sleep quality and affect did not change after the late morning session, $p>.081$.

These findings suggest that the effect of sleep quality on affective well-being depends on the time point when affect is assessed: The association of sleep quality with both positive affect and negative affect was stronger when the two measures were assessed at the same time point, but it did not decrease further throughout the day (i.e., from late morning to evening).

\section{Predicting sleep quality.}

Pre-registered analyses. Contrary to our hypotheses, both negative affect assessed in the evening, $b=-.056, p=.007$, and mean negative affect across the day $b=-.071, p=.035$, were associated with lower sleep quality reported in the next morning (see Table 3).

Examining the random effect associated with this predictor suggested that there were no statistically meaningful inter-individual differences in the size of this effect, $\chi^{2}(4)<7.56, p>$ .109. For tense arousal, only ratings obtained in the evening session, $b=-.042, p=.011$, but not mean ratings across the day, $b=-.045, p=.108$, were associated with worse subsequent sleep quality. Only the random effect for mean daily ratings, $\chi^{2}(4)=13.56, p=.009$, but not the random effect for evening ratings, $\chi^{2}(4)=8.27, p=.082$, was statistically significant. The 
pattern of results was unchanged in all sensitivity analyses with one exception: When removing the fixed and random effect of study day, daily tense arousal was statistically significantly associated with worse subsequent sleep quality as well.

In sum, results showed, largely contrary to our expectations, that both evening negative affect and daily negative affect were associated with poorer subsequent sleep quality. In addition, only evening, but not daily tense arousal was associated with subsequent sleep quality.

Exploratory analyses. Our pre-registered hypotheses had specifically targeted the effects of negative affect and tense arousal on sleep quality. We had no pre-registered hypotheses regarding associations of positive affect (either assessed in the evening, or mean positive affect across the day) with subsequent sleep quality. Exploratory analyses showed that both mean positive affect across the day, $b=.110, p=.002$, and positive affect assessed in the evening, $b=.052, p=.026$, were associated with better sleep quality the following night.

Dynamic structural equation model. We tested the dynamic interplay of subjective sleep variables (sleep quality, time in bed) and affective well-being (daily positive affect and daily negative affect) via DSEM. First, we aggregated the four daily affect measures (morning, late morning, afternoon, evening) into one average positive affect score and one average negative affect score per day and child. Next, we set up a model as schematically depicted in Figure 1. On the within-person level, autoregressive effects were estimated for all four variables (i.e., all variables were predicted by themselves at the previous day). Furthermore, sleep quality and sleep duration were predicted by previous day's (average) positive affect and negative affect. Daily positive and negative affect were predicted by sleep quality and time in bed of the previous night. For all within-person parameters (all four autoregressive parameters, the eight other regression coefficients and the four innovation 
variances), random effects were estimated. On the between-person level, correlations among the four intercepts were estimated.

DSEM requires a Bayesian estimator. For the present analyses, we kept the Mplus default (diffuse) priors. Two Markov Chain Monte Carlo (MCMC) chains were estimated with 3000 iterations per chain, of which 50\% were discarded as burn-in. A thinning factor of 50 was chosen to reduce the autocorrelation among subsequent MCMC draws. The results are based on the posterior distribution of 3000 iterations. We report point estimates (the median of the posterior parameter distribution) and associated $95 \%$ credible intervals. We report parameters as statistically significant (i.e., different from zero) if their $95 \%$ credible interval does not contain zero. Graphical inspection of the trace plots and the autoregressive plots suggested no irregularities. The maximal potential scale reduction (PSR) was 1.003, suggesting that the estimation of the two chains converged successfully (Hamaker et al., 2018).

Results (see Table 4 left column) showed positive autoregressive effects for all four variables. Time in bed did not predict next day's positive affect, $\beta=.023[-.013, .059]$, or negative affect, $\beta=.005[-.031, .039]$, and time in bed was not predicted by either positive affect, $\beta=-.009[-.065, .049]$, or negative affect of the previous day, $\beta=.020[-.038, .076]$. In contrast, better sleep quality was associated with both higher positive affect, $\beta=.099[.058$, $.139]$, and lower negative affect on the next day, $\beta=-.073[-.111,-.036]$. Vice versa, positive affect was associated with better sleep quality, $\beta=.102[.052, .153]$, and negative affect was associated with worse sleep quality in the following night, $\beta=-.088[-.137,-.040]$.

These findings suggest reciprocal relations between subjective sleep quality and affective well-being: After a night with better sleep quality than usual, children reported higher positive affect and lower negative affect throughout the day - even after controlling for affective well-being on the previous day. Vice versa, on days with higher positive and lower 
negative affect than usual, children reported better sleep quality the following night (after controlling for previous night's sleep quality).

\section{Study 2}

We aimed to replicate the findings reported in Study 1 in a separate sample. Because the sample reported in Könen et al. (2016) was slightly younger than the sample reported in Study 1, we drew a younger sample for Study 2. Study hypotheses were not pre-registered for Study 2. However, because the design was very similar, we employed the same analyses that had been preregistered for Study 1 in Study 2 as well. Additionally, we changed the assessment of affect in this study, which allowed to us to explore potential differences in the association of sleep quality with high and low arousal affect.

\section{Method}

Participants. Participating children $(N=84,55.9 \%$ boys $)$ were 8 to 10 years old $(M=$ 8.98 years, $S D=0.78$ ) and lived in [blinded], Germany, and surrounding areas. The majority of children $(n=79 ; 94.0 \%)$ were born in Germany and in most families $(n=63 ; 75.0 \%)$, German was the only or primary language spoken at home. Most of children's fathers were working full-time $(n=66 ; 78.6 \%)$ or part-time $(n=9 ; 10.7 \%)$; children's mothers were primarily employed in part-time $(n=52 ; 61.9 \%)$ or full-time $(n=30 ; 35.7 \%)$.

Procedure. Study 2 consisted of a pretest, an ambulatory assessment period across three school weeks and a posttest. Prior to the start of the study, children as well as their parents provided written informed consent and were informed that they could cancel participation any time without giving reasons. During the pretest, children received instructions on how to operate the study smartphone and how to respond to the items. Children also filled in demographic and trait questionnaires. During the ambulatory assessment period, children answered questions three times per day on the study smartphone for a total period of 21 days. Assessments took place in the morning, in the afternoon, and in the evening; all assessments occurred outside the school context. Morning sessions were 
scheduled between 6:45 am and 7:50 am during the week and between 6:45 am and 9:15 am during weekends. For the afternoon and the evening session, parents could choose between an earlier option $(3: 00 \mathrm{pm}-5: 15 \mathrm{pm}$ and 6:00 - 8:30 pm) and a later option (4:00 pm - 6:15 pm and 7:00 pm - 9:30 pm) determining the timing of the assessment. Assessments took between three minutes (morning assessment) and ten minutes (afternoon assessment) to complete. After the ambulatory assessment period, children returned the study smartphones and filled in a final set of questionnaires comprising self-report measures as well as feedback questions. Children obtained a gift card in the amount of $25 €$ as compensation for their participation. If they had completed more than $70 \%$ of all daily assessments, they received another gift card in the amount of $5 €$, and $10 €$ if they had completed more than $90 \%$ of all daily assessments. Compliance rates ranged from $79.1 \%$ (afternoon session) to $89.1 \%$ (evening session). The study was approved by the local ethics committee.

\section{Measurements.}

Momentary affect. Positive and negative affect were assessed with six items each, of which three were intended to capture high arousal affect (negative affect: afraid, nervous, uneasy; positive affect: active, interested, enthusiastic). The other six items were intended to measure low arousal affect (negative affect: unhappy, miserable, sad; positive affect: good, fantastic, content). For the main analyses, we averaged the six positive affect items ( $\omega$ within $=.78 / .81 / .79 ; \omega$ between $=.88 / .87 / .77)$ and the six negative affect items $(\omega$ within $=.77 /$ $.77 / .78 ; \omega$ between $=.95 / .95 / .95)$ at each measurement occasion. In exploratory analyses, we conducted the analyses separately for high arousal and low arousal positive and negative affect, respectively.

Sleep quality. The same three items were used to assess sleep quality as in Study 1. Reliability $(\omega)$ was estimated as .55 on the within-person and .81 on the between-person level.

Time in bed. Children again indicated when they went to bed last night and when they woke up today every morning. As in Study 1, we set wake up time to missing if the wake up 
time was later than the time point at which they filled in the morning questionnaire (268 of 1,495 wake up times set to missing), and we set bed time to missing if it was reported at a time point before the time stamp of the last questionnaire of the previous day ( 63 of 1,503 bed times set to missing). Time in bed was again computed as the difference between wake up time and bed time, and negative time in bed estimates $(n=20)$ were set to missing values.

Data analysis. We used the same modeling approach as in Study 1. Since there were only three assessments per day in this study, daily affect was computed as the average of these three (vs. four in Study 1) momentary assessments. See Table 5 for descriptive statistics of the study variables.

\section{Results and Discussion}

Predicting affect. For positive affect, findings on the fixed effects replicated results from Study 1: Better subjective sleep quality was associated with higher positive affect in the morning session, $b=.179, p<.001$, and in the evening session, $b=.124, p=.002$, but not in the afternoon session, $b=.056, p=.168$ (see Table 2 ). There was a statistically meaningful within-person association of better sleep quality with lower negative affect in the morning, $b$ $=-.099, p<.001$, but not in the evening, $b=-.041, p=.128$, replicating findings from Study

1. In contrast to results in Study 1, the within-person association between sleep quality and negative affect in the afternoon was not statistically meaningful, $b=.003, p=.924$. When removing the fixed and random time trends in sensitivity analyses, better sleep quality was additionally associated with higher positive affect in the afternoon, as well as lower negative affect in the afternoon and in the evening. All other effects of sleep quality did not change in all sensitivity analyses (see Online Supplement Tables S2 - S5).

We explored if the pattern of findings differed when considering high and low arousal affect separately. Detailed result of these analyses are reported in the Online Supplement (Tables S7 and S8). For negative affect, the pattern of within-person findings was identical for both high and low arousal: sleep quality and time in bed were associated with both, more high 
and low arousal negative affect in the morning, but unrelated to negative affect assessed later in the day. High and low positive affect in the morning and evening session were both significantly associated with better subjective sleep quality. For positive affect assessed in the afternoon, sleep quality was associated with more high arousal, $b=.096, p=.041$, but not low arousal positive affect, $b=.022, p=.612$.

Hence, Study 2 replicated the hypothesized positive effects of sleep quality on positive affect in the morning and evening assessment. As in Study 1, the association between sleep quality and afternoon positive affect was not statistically meaningful. In exploratory analyses, better sleep quality was related to higher subsequent high arousal (but unrelated to low arousal) positive affect in the afternoon. We further replicated the negative association between sleep quality and morning negative affect and the not significant association between sleep quality and evening negative affect. In contrast to findings from Study 1 (but in line with our hypotheses), the association between sleep quality and negative affect in the afternoon was not statistically significant. Table 6 summarizes the findings for the preregistered hypotheses from both studies.

Predicting sleep quality. There was no statistically meaningful within-person association between negative affect assessed in the evening and sleep quality rated in the next morning, $b=-.068, p=.118$ (see Online Supplement Table S9). The effect of evening negative affect on sleep quality remained statistically not significant, when targeting either only low arousal, $b=-.064, p=.107$, or high arousal negative affect, $b=-.012, p=.751$. However, average negative affect throughout the day was significantly related to worse sleep quality in the following night, $b=-.146, p=.006$. Findings for low and high arousal negative affect were comparable: Both, daily high arousal and daily low arousal negative affect predicted poorer subsequent sleep quality. Neither evening positive affect, $b=.046, p=.138$, nor average positive affect across the day, $b=.059, p=.187$, was significantly associated with subsequent sleep quality. 
Dynamic structural equation model. We used the same model and the same settings for the estimation of the DSEM as in Study 1. The two MCMC chains converged with a maximum PSR of 1.005. Replicating results from Study 1 (see Table 4, right column), better subjective sleep quality was associated with both higher daily positive affect, $\beta=.132[.082$, $.182]$, and lower daily negative affect, $\beta=-.061$ [-.105, -.015]. As in Study 1 , sleep quality was predicted by previous day's positive affect, $\beta=.089[.031, .150]$. In contrast to Study 1 , the effect of daily negative affect on subsequent sleep quality was not statistically meaningful, $\beta=-.045[-.110, .015]$. Splitting well-being into high and low arousal affect revealed the same pattern of results (see Online Supplement, Table S10).

In summary, results from the multilevel models showed that evening negative affect did not predict worse subsequent sleep quality, but daily negative affect did. However, findings from the DSEM showed that the effect of negative affect on subsequent sleep quality was no longer statistically meaningful, once daily positive affect and previous night's sleep quality were controlled for. DSEM findings hence replicated the reciprocal associations between positive affect and sleep quality, but not between negative affect and sleep quality.

\section{General Discussion}

Results across two ambulatory assessment studies conducted with school children between 8 and 11 years suggest rather consistent effects of self-reported sleep quality (but not self-reported time in bed) on affective well-being in the following morning: When children reported better sleep quality for the previous night, they reported higher momentary positive affect and lower momentary negative affect in the morning. The present study also examined if the effect of sleep quality on affective well-being diminished across the day. For negative affect, this seemed to be the case: In almost all models tested, sleep quality was unrelated to negative affect later the same day. Only in Study 1, there was some evidence for an effect on later negative affect, with lower negative affect reported in the afternoon after a better night's sleep. 
In contrast, sleep quality was associated with higher positive affect not only in the morning session, but also in the late morning session (only assessed in Study 1) and in the evening session (both studies). Interestingly, there was no evidence for a continuous decrease in sleep quality's effect on positive affect throughout the day and, in fact, sleep quality was consistently unrelated to afternoon positive affect, but then again positively associated with evening positive affect. Potentially, positive affect in the afternoon is more strongly tied to experiences that occurred earlier in the day (e.g., positive experiences with one's peers, Schmidt et al., 2020), reducing the impact of sleep on afternoon positive affect. Evening positive affect may then again be more strongly tied to last night's sleep quality since the effects of poor sleep might "catch up" on children before they go to bed. We note that, while this pattern of results is consistent across the two studies reported here, it partially stands in contrast to earlier findings that suggested a positive effect of sleep quality also on afternoon positive affect in children (Könen et al., 2016). Affective states vary quickly within a day as shown in prior ambulatory assessment research with adults (Crayen et al., 2012; Kuppens et al., 2010). To better understand the wax and wane of the association between sleep quality and positive affect, assessments of affect on a temporally more fine-grained resolution will be required in future research.

In a second set of analyses, we examined the prospective effects of affective wellbeing on subjective sleep quality the next night. Contrary to our hypotheses, higher negative affect (both in the evening assessment and average negative affect across the day) was meaningfully related to worse subsequent sleep quality in Study 1. Partially confirming our expectation on tense arousal, only tense arousal across the day, but not tense arousal assessed in the evening was associated with worse subjective sleep quality the following night. We had built the expectation for the specific role of tense arousal on prior work linking high arousal states to worse sleep (Szymusiak \& McGinty, 2008; Tavernier et al., 2016). Our results suggest, however, that the arousal component of the negative affect assessment does not seem 
to modulate whether or not negative affect predicts worse sleep. This was also shown in Study 2 , in which the pattern of results for high and low arousal negative affect predicting subjective sleep quality was identical. However, both for tense arousal in Study 1 and for negative affect in Study 2, only averaged assessments across the day (but not states assessed in the evening) emerged as a meaningful predictor of subjective sleep quality. One possible explanation for these results is that accumulated negative experiences throughout the day may have a stronger impact on subsequent sleep than more proximal momentary negative experiences. This phenomenon is known in stress research demonstrating that stressor accumulation predicts negative affective states above and beyond the occurrence of single stressors (Schilling \& Diehl, 2014). Findings from our DSEM analyses showed, however, that the effect of negative affect was not consistently statistically meaningful, once we controlled for daily positive affect and prior night's sleep quality. This finding is in line with previous work that has generally reported more consistent effects of positive (versus negative) affect on subsequent sleep quality (Konjarski et al., 2018), and it is also consistent with the respective findings in children's daily lives reported by Könen et al. (2016).

\section{Implications}

The present results have important implications for future research in developmental psychology. Our findings emphasize the need to separate positive and negative affect on the within-person level also in children as young as eight years: These two dimensions of affective well-being are not only separable psychometrically (Leonhardt et al., 2016) and differentially related to daily experiences (e.g., Schmidt et al., 2020), but they are also differentially associated with sleep quality. Hence, in order to obtain a more comprehensive picture of children's affective well-being, it is important to consider both positive and negative affect. Furthermore, our results add to prior work on adults (Cox et al., 2018), which showed that the association between sleep and well-being depends on the time of day when the assessment was taken. 
The somewhat inconsistent effect of negative affect on sleep quality hints towards potential moderators of this association that might explain the heterogeneity in findings across studies and analyses. First, random slopes associated with this within-person effect in some of the models tested suggest that this effect may be meaningful for some, but not other children. Second, it is also conceivable that the impact of negative affect varies within children across days as a function of day-level moderators. One potential candidate explaining heterogeneity within and/or between children might be pre-sleep perseverative cognitions (encompassing rumination about the past day or worries about the upcoming day), which might modulate the affect-sleep association in a way that negative states experienced across the day only translate into worse sleep quality if children ponder on these events. This explanation dovetails with results from a cross-sectional study on 57 youths with elevated anxiety levels (7-14 year olds), which found a negative association of (child-reported) pre-sleep perseverative cognitions with (parent-reported) sleep duration and a positive association with (parent-reported) sleep problems (Alfano et al., 2010). Future research is needed to more closely examine the role of perseverative cognitions such as worry and rumination, or related constructs such as anticipatory stress (Neupert et al., 2019) for the interplay of negative affective states and sleep quality. In addition, future research should also target potential person-level moderators (e.g., poor sleep hygiene, chronotype, household structure, parental oversight, pubertal development) that might account for between-person differences in the observed withinperson dynamics of sleep and affect. Further, including daily reports on parental sleep and daily parent-child interactions in addition to children's self-reports might help to determine the role of parents for children's sleep schedules. Crossover effects from parental variables to children's sleep parameters may play an important role in late childhood.

Finally, one particularly interesting avenue for future research will be to target potentially downstream consequences of the dynamic interplay between sleep and affective well-being for developmental outcomes. For example, the association between daily tense 
arousal and subsequent sleep quality was stronger for some children than for others.

Potentially, those children whose sleep quality is more strongly tied to tense arousal might in the long run exhibit negative developmental outcomes. Related work suggests that individuals who show a particularly strong increase in negative affect when they experience a minor stressor in their everyday lives show, for example, increases in depressive symptoms (Charles et al., 2013) and decreases in health outcomes (Piazza et al., 2013) ten years later. Transferring these ideas to the developmental context of late childhood, it might be that children whose sleep is particularly impacted by negative affective states might show suboptimal longitudinal changes throughout puberty and beyond. For these children, a vicious circle between negative affective states and poor sleep might set off developmental cascades that culminate in internalizing or externalizing problems, and academic adjustment problems. Hence, better understanding the heterogeneity in this dynamic interplay - both between children, but also from day to day - is important to more fully grasp this association and to potentially develop tailored interventions to improve children's sleep quality.

\section{Limitations}

In interpreting the results from two comprehensive ambulatory assessment studies in late childhood, a number of limitations needs to be considered, however. First, although the two studies were comparable in many aspects to the study they intended to replicate (Könen et al., 2016), results from this prior work could not all be replicated. This may be attributed to a number of differences between the original study and the present work such as participants' age, assessment time of the study in the course of the school year, or the sampling scheme, in particular the time point and context at which affective well-being was assessed (in school vs. out of school). Further, measurement error on the within-person level, in particular in the assessment of sleep quality, might have attenuated replication chances. Second, we included subjective reports of sleep quality and sleep duration (operationalized as time in bed) only. Prior work suggests a stronger association of affective well-being with subjective (versus 
objective) sleep measures (Konjarski et al., 2018), and therefore it might be expected that the effects of objective sleep parameters are less strongly associated with affective experiences (McCrae et al., 2008). This pattern of results may therefore not generalize to situations in which only objective, but no subjective sleep indicators are assessed. Furthermore, time in bed in late childhood is to some extent externally regulated (by the parents) and may hence not be as strongly related to children's subjective experiences as was subjective sleep quality. In addition, sleep onset latency (the time from going to bed until falling asleep) was not targeted in this work and might be a relevant construct for future research. Third, even though the present findings provide some evidence for the temporal direction of effects, the present design cannot unequivocally determine causal effects. Ultimately, experimental approaches on the day-to-day level are needed to tease apart cause and effect in intensive longitudinal studies as used in the present work (Klasnja et al., 2015; Schmiedek \& Neubauer, 2020). Fourth, results are based on a convenience sample that is likely not representative of the general population. Fifth, we tested for inter-individual differences in the within-person effects via likelihood ratio tests. These tests have been reported as too conservative when a parameter is constrained at its boundary (as was the case in the present analyses when the random slope variance was fixed to 0; Stoel et al., 2006). In addition, while statistical power in our design was likely adequate to detect even small fixed effects, larger sample sizes might be needed to test for between-person differences in the within-person interplay between sleep quality and well-being, and to examine predictors of such differences.

\section{Conclusions}

Subjective sleep quality (but not time in bed) and affective well-being in children's (811 years) daily lives were reciprocally related. The positive effects of a good night's sleep on positive affect were more enduring throughout the day than the respective effects on negative affect. Positive affect during the day was positively associated with subsequent nightly sleep quality. Negative affect had a somewhat less consistent effect on subsequent nightly sleep 
quality, which potentially indicates the existence of moderators of this association. Taken together, the findings suggest a close relation of subjective sleep quality and positive affect, which strengthens the idea behind interventions targeting both, children's sleep and wellbeing. 


\section{References}

Åkerstedt, T., Orsini, N., Petersen, H., Axelsson, J., Lekander, M., \& Kecklund, G. (2012). Predicting sleep quality from stress and prior sleep--a study of day-to-day covariation across six weeks. Sleep Medicine, 13(6), 674-679. https://doi.org/10.1016/j.sleep.2011.12.013

Alfano, C. A., Pina, A. A., Zerr, A. A., \& Villalta, I. K. (2010). Pre-sleep arousal and sleep problems of anxiety-disordered youth. Child Psychiatry \& Human Development, 41(2), 156-167. https://doi.org/10.1007/s10578-009-0158-5

Asparouhov, T., Hamaker, E. L., \& Muthén, B. (2017). Dynamic structural equation models. Structural Equation Modeling: A Multidisciplinary Journal, 25(3), 359-388. https://doi.org/10.1080/10705511.2017.1406803

Astill, R. G., van der Heijden, K. B., van Ijzendoorn, M. H., \& van Someren, E. J. W. (2012). Sleep, cognition, and behavioral problems in school-age children: A century of research meta-analyzed. Psychological Bulletin, 138(6), 1109-1138. https://doi.org/10.1037/a0028204

Brans, K., Koval, P., Verduyn, P., Lim, Y. L., \& Kuppens, P. (2013). The regulation of negative and positive affect in daily life. Emotion (Washington, D.C.), 13(5), 926-939. https://doi.org/10.1037/a0032400

Campbell, I. G., \& Feinberg, I. (2009). Longitudinal trajectories of non-rapid eye movement delta and theta EEG as indicators of adolescent brain maturation. Proceedings of the National Academy of Sciences, 106(13), 5177-5180. https://doi.org/10.1073/pnas.0812947106

Carskadon, M. A [M. A.], Vieira, C., \& Acebo, C. (1993). Association between puberty and delayed phase preference. Sleep, 16(3), 258-262. https://doi.org/10.1093/sleep/16.3.258 
Charles, S. T., Piazza, J. R., Mogle, J., Sliwinski, M. J., \& Almeida, D. M. (2013). The wear and tear of daily stressors on mental health. Psychological Science, 24(5), 733-741. https://doi.org/10.1177/0956797612462222

Cox, R. C., Sterba, S. K., Cole, D. A., Upender, R. P., \& Olatunji, B. O. (2018). Time of day effects on the relationship between daily sleep and anxiety: An ecological momentary assessment approach. Behaviour Research and Therapy, 111, 44-51. https://doi.org/10.1016/j.brat.2018.09.008

Crayen, C., Eid, M., Lischetzke, T., Courvoisier, D. S., \& Vermunt, J. K. (2012). Exploring dynamics in mood regulation--mixture latent Markov modeling of ambulatory assessment data. Psychosomatic Medicine, 74(4), 366-376.

https://doi.org/10.1097/PSY.0b013e31825474cb

Curcio, G., Ferrara, M., \& Gennaro, L. de (2006). Sleep loss, learning capacity and academic performance. Sleep Medicine Reviews, 10(5), 323-337. https://doi.org/10.1016/j.smrv.2005.11.001

Deliens, G., Gilson, M., \& Peigneux, P. (2014). Sleep and the processing of emotions. Experimental Brain Research, 232(5), 1403-1414. https://doi.org/10.1007/s00221-014$3832-1$

El-Sheikh, M., Philbrook, L. E., Kelly, R. J., Hinnant, J. B., \& Buckhalt, J. A. (2019). What does a good night's sleep mean? Nonlinear relations between sleep and children's cognitive functioning and mental health. Sleep, 42(6), 687. https://doi.org/10.1093/sleep/zsz078

Fredriksen, K., Rhodes, J., Reddy, R., \& Way, N. (2004). Sleepless in Chicago: Tracking the effects of adolescent sleep loss during the middle school years. Child Development, 75(1), 84-95. https://doi.org/10.1111/j.1467-8624.2004.00655.x 
Fuligni, A. J., \& Hardway, C. (2006). Daily variation in adolescents' sleep, activities, and psychological well-being. Journal of Research on Adolescence, 16(3), 353-378. https://doi.org/10.1111/j.1532-7795.2006.00498.x

Geldhof, G. J., Preacher, K. J., \& Zyphur, M. J. (2014). Reliability estimation in a multilevel confirmatory factor analysis framework. Psychological Methods, 19(1), 72-91. https://doi.org/10.1037/a0032138

Hamaker, E. L., Asparouhov, T., Brose, A., Schmiedek, F., \& Muthén, B. (2018). At the frontiers of modeling intensive longitudinal data: Dynamic structural equation models for the affective measurements from the COGITO study. Multivariate Behavioral Research, 53(6), 820-841. https://doi.org/10.1080/00273171.2018.1446819

Hill, C. M., Hogan, A. M., \& Karmiloff-Smith, A. (2007). To sleep, perchance to enrich learning? Archives of Disease in Childhood, 92(7), 637-643. https://doi.org/10.1136/adc.2006.096156

Kahn, M., Sheppes, G., \& Sadeh, A. (2013). Sleep and emotions: Bidirectional links and underlying mechanisms. International Journal of Psychophysiology : Official Journal of the International Organization of Psychophysiology, 89(2), 218-228. https://doi.org/10.1016/j.ijpsycho.2013.05.010

Kalak, N., Lemola, S., Brand, S., Holsboer-Trachsler, E., \& Grob, A. (2014). Sleep duration and subjective psychological well-being in adolescence: A longitudinal study in Switzerland and Norway. Neuropsychiatric Disease and Treatment, 1199-1207. https://doi.org/10.2147/NDT.S62533

Kelly, R. J., \& El-Sheikh, M. (2014). Reciprocal relations between children's sleep and their adjustment over time. Developmental Psychology, 50(4), 1137-1147. https://doi.org/10.1037/a0034501 
Klasnja, P., Hekler, E. B., Shiffman, S., Boruvka, A., Almirall, D., Tewari, A., \& Murphy, S. A. (2015). Microrandomized trials: An experimental design for developing just-in-time adaptive interventions. Health Psychology, 34(Suppl), 1220-1228. https://doi.org/10.1037/hea0000305

Könen, T., Dirk, J., Leonhardt, A., \& Schmiedek, F. (2016). The interplay between sleep behavior and affect in elementary school children's daily life. Journal of Experimental Child Psychology, 150, 1-15. https://doi.org/10.1016/j.jecp.2016.04.003

Konjarski, M., Murray, G., Lee, V. V., \& Jackson, M. L. (2018). Reciprocal relationships between daily sleep and mood: A systematic review of naturalistic prospective studies. Sleep Medicine Reviews, 42, 47-58. https://doi.org/10.1016/j.smrv.2018.05.005

Kouros, C. D., \& El-Sheikh, M. (2015). Daily mood and sleep: Reciprocal relations and links with adjustment problems. Journal of Sleep Research, 24(1), 24-31. https://doi.org/10.1111/jsr.12226

Kramer, A. C., Neubauer, A. B., Leonhardt, A., Dirk, J., Brose, A., \& Schmiedek, F. (2020). Ambulatory Assessment of Rumination and Worry: Capturing Perseverative Cognitions in Children's Daily Life. https://psyarxiv.com/hgy9b/ https://doi.org/10.31234/osf.io/hgy9b

Kuppens, P., Oravecz, Z., \& Tuerlinckx, F. (2010). Feelings change: Accounting for individual differences in the temporal dynamics of affect. Journal of Personality and Social Psychology, 99(6), 1042-1060. https://doi.org/10.1037/a0020962

Kurth, S., Jenni, O. G., Riedner, B. A., Tononi, G., Carskadon, M. A [Mary A.], \& Huber, R. (2010). Characteristics of sleep slow waves in children and adolescents. Sleep, 33(4), 475480. https://doi.org/10.1093/sleep/33.4.475

Leonhardt, A., Könen, T., Dirk, J., \& Schmiedek, F. (2016). How differentiated do children experience affect? An investigation of the within- and between-person structure of 
children's affect. Psychological Assessment, 28(5), 575-585.

https://doi.org/10.1037/pas0000195

McCrae, C. S., McNamara, J. P. H., Rowe, M. A., Dzierzewski, J. M., Dirk, J., Marsiske, M., \& Craggs, J. G. (2008). Sleep and affect in older adults: Using multilevel modeling to examine daily associations. Journal of Sleep Research, 17(1), 42-53. https://doi.org/10.1111/j.1365-2869.2008.00621.x

Meijer, A. M., Reitz, E., Deković, M., van den Wittenboer, G. L. H., \& Stoel, R. D. (2010). Longitudinal relations between sleep quality, time in bed and adolescent problem behaviour. Journal of Child Psychology and Psychiatry, and Allied Disciplines, 51(11), 1278-1286. https://doi.org/10.1111/j.1469-7610.2010.02261.x

Meltzer, L. J., Biggs, S., Reynolds, A., Avis, K. T., Crabtree, V. M., \& Bevans, K. B. (2012). The Children's Report of Sleep Patterns--Sleepiness Scale: A self-report measure for school-aged children. Sleep Medicine, 13(4), 385-389. https://doi.org/10.1016/j.sleep.2011.12.004

Murray, G., Allen, N. B., \& Trinder, J. (2002). Mood and the circadian system: Investigation of a circadian component in positive affect. Chronobiology International, 19(6), 11511169. https://doi.org/10.1081/CBI-120015956

Neupert, S. D., Neubauer, A. B., Scott, S. B., Hyun, J., \& Sliwinski, M. J. (2019). Back to the Future: Examining age differences in processes before stressor exposure. The Journals of Gerontology: Series B, 74(1), 1-6. https://doi.org/10.1093/geronb/gby074

Ong, A. D., Kim, S., Young, S., \& Steptoe, A. (2017). Positive affect and sleep: A systematic review. Sleep Medicine Reviews, 35, 21-32. https://doi.org/10.1016/j.smrv.2016.07.006

Paavonen, E. J., Solantaus, T., Almqvist, F., \& Aronen, E. T. (2003). Four-year follow-up study of sleep and psychiatric symptoms in preadolescents: Relationship of persistent and temporary sleep problems to psychiatric symptoms. Journal of Developmental \& 
Behavioral Pediatrics, 24(5), 307-314. https://doi.org/10.1097/00004703-20031000000001

Paruthi, S., Brooks, L. J., D'Ambrosio, C., Hall, W. A., Kotagal, S., Lloyd, R. M., Malow, B. A., Maski, K., Nichols, C., Quan, S. F., Rosen, C. L., Troester, M. M., \& Wise, M. S. (2016). Consensus statement of the American Academy of Sleep Medicine on the recommended amount of sleep for healthy children: Methodology and discussion. Journal of Clinical Sleep Medicine : JCSM : Official Publication of the American Academy of Sleep Medicine, 12(11), 1549-1561. https://doi.org/10.5664/jcsm.6288

Peltz, J. S., Rogge, R. D., Pugach, C. P., \& Strang, K. (2016). Bidirectional associations between sleep and anxiety symptoms in emerging adults in a residential College setting. Emerging Adulthood, 5(3), 204-215. https://doi.org/10.1177/2167696816674551

Petersen, A. C., Crockett, L., Richards, M., \& Boxer, A. (1988). A self-report measure of pubertal status: Reliability, validity, and initial norms. Journal of Youth and Adolescence, 17(2), 117-133. https://doi.org/10.1007/BF01537962

Piazza, J. R., Charles, S. T., Sliwinski, M. J., Mogle, J., \& Almeida, D. M. (2013). Affective reactivity to daily stressors and long-term risk of reporting a chronic physical health condition. Annals of Behavioral Medicine : A Publication of the Society of Behavioral Medicine, 45(1), 110-120. https://doi.org/10.1007/s12160-012-9423-0

Pinheiro, J., Bates, D., DebRoy, S., Sarkar, D., \& R. Development Core Team. (2019). nlme: Linear and nonlinear mixed effects models $R$. package version 3.1-142.

Schilling, O. K., \& Diehl, M. (2014). Reactivity to stressor pile-up in adulthood: Effects on daily negative and positive affect. Psychology and Aging, 29(1), 72-83. https://doi.org/10.1037/a0035500

Schmidt, A., Neubauer, A. B., Dirk, J., \& Schmiedek, F. (2020). The bright and the dark side of peer relationships: Differential effects of relatedness satisfaction and frustration at 
school on affective well-being in children's daily lives. Developmental Psychology. Advance online publication. https://doi.org/10.1037/dev0000997

Schmiedek, F., \& Neubauer, A. B. (2020). Experiments in the wild: Introducing the withinperson encouragement design. Multivariate Behavioral Research, 55(2), 256-276. https://doi.org/10.1080/00273171.2019.1627660

Schwerdtle, B., Roeser, K., Kübler, A., \& Schlarb, A. A. (2010). Validierung und psychometrische Eigenschaften der deutschen Version des Sleep Self Report (SSR-DE). Somnologie - Schlafforschung Und Schlafmedizin, 14(4), 267-274. https://doi.org/10.1007/s11818-010-0496-3

Steptoe, A., O'Donnell, K., Marmot, M., \& Wardle, J. (2008). Positive affect, psychological well-being, and good sleep. Journal of Psychosomatic Research, 64(4), 409-415. https://doi.org/10.1016/j.jpsychores.2007.11.008

Stoel, R. D., Garre, F. G., Dolan, C., \& van den Wittenboer, G. (2006). On the likelihood ratio test in structural equation modeling when parameters are subject to boundary constraints. Psychological Methods, 11(4), 439-455. https://doi.org/10.1037/1082-989X.11.4.439

Szymusiak, R., \& McGinty, D. (2008). Hypothalamic regulation of sleep and arousal. Annals of the New York Academy of Sciences, 1129, 275-286. https://doi.org/10.1196/annals.1417.027

Tavernier, R., Choo, S. B., Grant, K., \& Adam, E. K. (2016). Daily affective experiences predict objective sleep outcomes among adolescents. Journal of Sleep Research, 25(1), 6269. https://doi.org/10.1111/jsr.12338

Trull, T. J., \& Ebner-Priemer, U. (2013). Ambulatory assessment. Annual Review of Clinical Psychology, 151-176. https://doi.org/10.1146/annurev-clinpsy-050212-185510 van Zundert, R. M. P., van Roekel, E., Engels, R. C. M. E., \& Scholte, R. H. J. (2015). Reciprocal associations between adolescents' night-time sleep and daytime affect and the 
role of gender and depressive symptoms. Journal of Youth and Adolescence, 44(2), 556569. https://doi.org/10.1007/s10964-013-0009-3

Walden, T. A., Harris, V. S., \& Catron, T. F. (2003). How I feel: A self-report measure of emotional arousal and regulation for children. Psychological Assessment, 15(3), 399-412. https://doi.org/10.1037/1040-3590.15.3.399

Wang, L., \& Maxwell, S. E. (2015). On disaggregating between-person and within-person effects with longitudinal data using multilevel models. Psychological Methods, 20(1), 6383. https://doi.org/10.1037/met0000030

Watzlawik, M. (2009). Die Erfassung des Pubertätsstatus anhand der Pubertal Development Scale [Assessing pubertal status with the Pubertal Development Scale: First steps towards an evaluation of a German translation]. Diagnostica, 55(1), 55-65. https://doi.org/10.1026/0012-1924.55.1.55

Weise, S., Ong, J., Tesler, N. A., Kim, S., \& Roth, W. T. (2013). Worried sleep: 24-h monitoring in high and low worriers. Biological Psychology, 94(1), 61-70. https://doi.org/10.1016/j.biopsycho.2013.04.009

Wild-Hartmann, J. A. de, Wichers, M., van Bemmel, A. L., Derom, C., Thiery, E., Jacobs, N., van Os, J., \& Simons, C. J. P. (2013). Day-to-day associations between subjective sleep and affect in regard to future depression in a female population-based sample. British Journal of Psychiatry, 202(6), 407-412. https://doi.org/10.1192/bjp.bp.112.123794

Wilhelm, P., \& Schoebi, D. (2007). Assessing mood in daily life. European Journal of Psychological Assessment, 23(4), 258-267. https://doi.org/10.1027/1015-5759.23.4.258 
Table 1

Descriptive Statistics Study 1

\begin{tabular}{|c|c|c|c|c|c|c|c|c|c|c|c|c|c|c|}
\hline & \multirow[b]{3}{*}{ Sleep quality } & \multirow[b]{2}{*}{$\begin{array}{c}\text { Mean } \\
\text { (SD } \\
\text { within, } \\
\text { SD } \\
\text { between) }\end{array}$} & \multirow[b]{2}{*}{ ICC } & \multicolumn{11}{|c|}{ Correlations } \\
\hline & & & & 1 & $?$ & 3 & 4 & 5 & 6 & & 8 & 9 & 10 & 11 \\
\hline 1 & & $\begin{array}{c}3.76 \\
(0.771 \\
0.625)\end{array}$ & .397 & & .128 & $.548 *$ & $.528 *$ & $.517 *$ & $.492 *$ & $-.505^{*}$ & $-.475 *$ & $-.451 *$ & $-.454^{*}$ & $-.484 *$ \\
\hline 2 & Time in bed & $\begin{array}{c}9.16 \\
(1.124 \\
0.660)\end{array}$ & .257 & .026 & & .152 & .205 & .194 & .192 & -.068 & -.016 & -.029 & -.015 & -.077 \\
\hline 3 & PA morning & $\begin{array}{c}3.81 \\
(0.904 \\
0.817)\end{array}$ & .450 & $.245^{*}$ & .043 & & $.940 *$ & $.919 *$ & $.934 *$ & $-.233 *$ & -.189 & -.146 & -.139 & -.149 \\
\hline 4 & $\begin{array}{l}\text { PA late } \\
\text { morning }\end{array}$ & $\begin{array}{c}3.93 \\
(0.913 \\
0.775)\end{array}$ & .419 & $.140 *$ & .016 & $.336^{*}$ & & $.976^{*}$ & $.987 *$ & -.158 & -.120 & -.096 & -.091 & -.112 \\
\hline 5 & PA afternoon & $\begin{array}{c}3.82 \\
(0.968 \\
0.764)\end{array}$ & .383 & $.090 *$ & .060 & $.255^{*}$ & $.355^{*}$ & & $.993 *$ & -.140 & -.095 & -.077 & -.060 & -.089 \\
\hline 6 & PA evening & $\begin{array}{c}3.88 \\
(0.957 \\
0.778)\end{array}$ & .398 & $.101 *$ & .001 & $.281 *$ & $.301 *$ & $.309 *$ & & -.144 & -.115 & -.089 & -.079 & -.091 \\
\hline 7 & NA morning & $\begin{array}{c}1.91 \\
(0.924 \\
0.807)\end{array}$ & .433 & $-.239 *$ & -.017 & -.122 & $-.092 *$ & -.024 & -.012 & & $.943 *$ & $.926 *$ & $.957 *$ & $.890 *$ \\
\hline
\end{tabular}




\begin{tabular}{|c|c|c|c|c|c|c|c|c|c|c|c|c|c|c|}
\hline 8 & $\begin{array}{l}\text { NA late } \\
\text { morning }\end{array}$ & $\begin{array}{c}1.98 \\
(0.959 \\
0.779)\end{array}$ & .398 & $-.099 *$ & $-.072 *$ & -.029 & $-.216 *$ & $-.093 *$ & -.053 & $.386^{*}$ & & $.970 *$ & $.976 *$ & $.905 *$ \\
\hline 9 & NA afternoon & $\begin{array}{c}2.06 \\
(1.021, \\
0.811)\end{array}$ & .387 & $-.111 *$ & .037 & .039 & $-.083 *$ & $-.178 *$ & .006 & & $.328 *$ & & $.986 *$ & $.909 *$ \\
\hline 10 & NA evening & $\begin{array}{c}2.05 \\
(1.003, \\
0.832)\end{array}$ & .408 & $-.103 *$ & .000 & .035 & -.019 & -.023 & & & $.283^{*}$ & $.379 *$ & & $.910 *$ \\
\hline 11 & $\begin{array}{l}\text { Tense arousal } \\
\text { evening }\end{array}$ & $\begin{array}{c}2.20 \\
(1.213, \\
0.885)\end{array}$ & .347 & $-.102 *$ & .029 & .016 & -.023 & -.001 & -.052 & $.237^{*}$ & $.211 *$ & $.278 *$ & $.611 *$ & \\
\hline
\end{tabular}

Note. Table depicts descriptive statistics. Correlations in the upper diagonal refer to the between-person level; correlations in the lower diagonal refer to the within-person level. $\mathrm{ICC}=$ intra-class correlation; $\mathrm{PA}=$ positive affect; $\mathrm{NA}=$ negative affect.

$* p<.05 . N=108$. 
Table 2

Multilevel Models (Predicting Affect)

\begin{tabular}{|c|c|c|c|c|c|c|c|c|}
\hline & \multicolumn{8}{|c|}{ Positive Affect } \\
\hline & \multicolumn{2}{|c|}{ Morning } & \multicolumn{2}{|c|}{ Late morning } & \multicolumn{2}{|c|}{ Afternoon } & \multicolumn{2}{|c|}{ Evening } \\
\hline & $\begin{array}{c}\text { Study 1 } \\
\text { Model 1a }\end{array}$ & $\begin{array}{c}\text { Study } 2 \\
\text { Model 1c }\end{array}$ & $\begin{array}{c}\text { Study } 1 \\
\text { Model 2a }\end{array}$ & Study 2 & $\begin{array}{c}\text { Study 1 } \\
\text { Model 3a }\end{array}$ & $\begin{array}{c}\text { Study } 2 \\
\text { Model 3c }\end{array}$ & $\begin{array}{c}\text { Study } 1 \\
\text { Model 4a } \\
\end{array}$ & $\begin{array}{r}\text { Study } 2 \\
\text { Model 4c }\end{array}$ \\
\hline \multicolumn{9}{|l|}{ Fixed Effects } \\
\hline Intercept & $\begin{array}{l}3.993 * \\
(.096)\end{array}$ & $\begin{array}{l}3.712 * \\
(.091)\end{array}$ & $\begin{array}{l}4.179 * \\
(.092)\end{array}$ & - & $\begin{array}{l}4.112 * \\
(.101)\end{array}$ & $\begin{array}{l}3.865 * \\
(.092)\end{array}$ & $\begin{array}{l}4.132 * \\
(.099)\end{array}$ & $\begin{array}{l}3.805 * \\
(.091)\end{array}$ \\
\hline Study day & $\begin{array}{l}-0.009 \\
(.005)\end{array}$ & $\begin{array}{l}0.001 \\
(.006)\end{array}$ & $\begin{array}{l}-0.026 * \\
(.005)\end{array}$ & - & $\begin{array}{l}-0.022^{*} \\
(.005)\end{array}$ & $\begin{array}{l}-0.014 * \\
(.007)\end{array}$ & $\begin{array}{l}-0.017 * \\
(.005)\end{array}$ & $\begin{array}{l}-0.014 * \\
(.007)\end{array}$ \\
\hline School day & $\begin{array}{l}-0.041 \\
(.057)\end{array}$ & $\begin{array}{l}-0.032 \\
(.043)\end{array}$ & $\begin{array}{l}0.069 \\
(.061)\end{array}$ & - & $\begin{array}{l}-0.051 \\
(.075)\end{array}$ & $\begin{array}{l}-0.018 \\
(.062)\end{array}$ & $\begin{array}{l}-0.061 \\
(.070)\end{array}$ & $\begin{array}{l}-0.030 \\
(.053)\end{array}$ \\
\hline \multicolumn{9}{|l|}{ Within-person effects } \\
\hline Sleep quality & $\begin{array}{l}0.250 * \\
(.041)\end{array}$ & $\begin{array}{l}0.179 * \\
(.042)\end{array}$ & $\begin{array}{l}0.131 * \\
(.030)\end{array}$ & & $\begin{array}{l}0.067 \\
(.041)\end{array}$ & $\begin{array}{l}0.056 \\
(.041)\end{array}$ & $\begin{array}{l}0.093 * \\
(.034)\end{array}$ & $\begin{array}{l}0.124^{*} \\
(.039)\end{array}$ \\
\hline Time in bed & $\begin{array}{l}0.020 \\
(.018)\end{array}$ & $\begin{array}{l}-0.023 \\
(.018)\end{array}$ & $\begin{array}{l}0.008 \\
(.019)\end{array}$ & - & $\begin{array}{l}0.040 \\
(.023)\end{array}$ & $\begin{array}{l}0.002 \\
(.025)\end{array}$ & $\begin{array}{l}-0.017 \\
(.023)\end{array}$ & $\begin{array}{l}0.025 \\
(.022)\end{array}$ \\
\hline Sleep quality & $\begin{array}{l}0.625^{*} \\
(.101)\end{array}$ & $\begin{array}{l}0.267 * \\
(.134)\end{array}$ & $\begin{array}{l}0.524^{*} \\
(.097)\end{array}$ & - & $\begin{array}{l}0.523^{*} \\
(.096)\end{array}$ & $\begin{array}{l}0.223 \\
(.130)\end{array}$ & $\begin{array}{l}0.504 * \\
(.101)\end{array}$ & $\begin{array}{l}0.240 \\
(.138)\end{array}$ \\
\hline Time in bed & $\begin{array}{l}0.036 \\
(.089) \\
\end{array}$ & $\begin{array}{c}-0.123 \\
(.100) \\
\end{array}$ & $\begin{array}{l}0.118 \\
(.086) \\
\end{array}$ & - & $\begin{array}{l}0.099 \\
(.084) \\
\end{array}$ & $\begin{array}{l}0.015 \\
(.096) \\
\end{array}$ & $\begin{array}{l}0.129 \\
(.091) \\
\end{array}$ & $\begin{array}{l}-0.041 \\
(.102) \\
\end{array}$ \\
\hline \multicolumn{9}{|l|}{$\begin{array}{l}\text { Random Effects } \\
\text { (Standard Deviations) }\end{array}$} \\
\hline Intercept & 0.741 & 0.722 & 0.634 & - & 0.593 & 0.601 & 0.625 & 0.660 \\
\hline Study day & 0.043 & 0.051 & 0.048 & - & 0.040 & 0.046 & 0.041 & 0.052 \\
\hline Sleep quality & 0.286 & 0.252 & 0.090 & - & 0.188 & 0.008 & 0.052 & 0.129 \\
\hline Residual (Level 1) & 0.760 & 0.590 & 0.789 & - & 0.911 & 0.788 & 0.889 & 0.716 \\
\hline
\end{tabular}




\section{Fixed Effects}

Intercept

Study day

School day

Within-person effects

Sleep quality

Time in bed

Between-person effects

Sleep quality

Time in bed

\section{Random Effects}

(Standard Deviations)

Intercept

Study day

Sleep quality

Residual (Level 1)

\begin{tabular}{|c|c|c|c|c|c|c|c|}
\hline \multicolumn{8}{|c|}{ Negative Affect } \\
\hline \multicolumn{2}{|c|}{ Morning } & \multicolumn{2}{|c|}{ Late morning } & \multicolumn{2}{|c|}{ Afternoon } & \multicolumn{2}{|c|}{ Evening } \\
\hline $\begin{array}{c}\text { Study 1 } \\
\text { Model 1b }\end{array}$ & $\begin{array}{c}\text { Study } 2 \\
\text { Model 1d }\end{array}$ & $\begin{array}{c}\text { Study } 1 \\
\text { Model 2b }\end{array}$ & Study 2 & $\begin{array}{c}\text { Study 1 } \\
\text { Model 3b }\end{array}$ & $\begin{array}{c}\text { Study } 2 \\
\text { Model 3d }\end{array}$ & $\begin{array}{c}\text { Study } 1 \\
\text { Model 4b }\end{array}$ & $\begin{array}{c}\text { Study } 2 \\
\text { Model 4d }\end{array}$ \\
\hline $\begin{array}{l}1.586^{*} \\
(.078)\end{array}$ & $\begin{array}{l}1.361 * \\
(.047)\end{array}$ & $\begin{array}{l}1.685^{*} \\
(.081)\end{array}$ & - & $\begin{array}{l}1.749 * \\
(.109)\end{array}$ & $\begin{array}{l}1.379 * \\
(.060)\end{array}$ & $\begin{array}{l}1.832 * \\
(.094)\end{array}$ & $\begin{array}{l}1.404 * \\
(.057)\end{array}$ \\
\hline $0.029 *$ & 0.002 & $0.030 *$ & - & $0.023 *$ & 0.004 & $0.024 *$ & -0.002 \\
\hline$(.005)$ & $(.005)$ & $(.005)$ & & $(.006)$ & $(.006)$ & $(.005)$ & $(.005)$ \\
\hline-0.019 & 0.028 & -0.119 & - & 0.001 & $0.086^{*}$ & -0.131 & 0.031 \\
\hline$(.058)$ & $(.030)$ & $(.064)$ & & $(.073)$ & $(.042)$ & $(.068)$ & $(.034)$ \\
\hline$-0.241^{*}$ & $-0.099 *$ & -0.060 & - & $-0.105^{*}$ & 0.003 & -0.041 & -0.041 \\
\hline$(.038)$ & $(.025)$ & $(.034)$ & & $(.045)$ & $(.031)$ & $(.034)$ & $(.027)$ \\
\hline 0.003 & $-0.036^{*}$ & -0.028 & & $0.046^{*}$ & -0.023 & 0.025 & -0.022 \\
\hline (.018) & $(.012)$ & $(.020)$ & & $(.023)$ & $(.017)$ & $(.023)$ & $(.014)$ \\
\hline
\end{tabular}

\begin{tabular}{|c|c|c|c|c|c|c|}
\hline $\begin{array}{l}-0.498 * \\
(.083)\end{array}$ & $\begin{array}{l}-0.286^{*} \\
(.073)\end{array}$ & $\begin{array}{l}-0.435^{*} \\
(.082)\end{array}$ & $\begin{array}{l}-0.487 * \\
(.111)\end{array}$ & $\begin{array}{l}-0.260 * \\
(.085)\end{array}$ & $\begin{array}{l}-0.487 * \\
(.101)\end{array}$ & $\begin{array}{l}-0.269 * \\
(.080)\end{array}$ \\
\hline $\begin{array}{l}0.156^{*} \\
.073)\end{array}$ & $\begin{array}{l}-0.155^{*} \\
(.053)\end{array}$ & $\begin{array}{c}-0.083 \\
(.074)\end{array}$ & $\begin{array}{l}-0.017 \\
(.098)\end{array}$ & $\begin{array}{l}-0.165^{*} \\
(.063)\end{array}$ & $\begin{array}{l}-0.118 \\
(.092)\end{array}$ & $\begin{array}{l}-0.121 * \\
(.059)\end{array}$ \\
\hline
\end{tabular}

Note. Table depicts point estimates (unstandardized coefficients; standard errors of fixed effects in parentheses). Number of observations $=1,470$ 1,766 (Study 1), 980 - 1,157 (Study 2); number of participants = 107-108 (Study 1), 83-84 (Study 2). Significance level for single random variances is not depicted.

$* p<.05$ 
Table 3

Multilevel Models (Predicting Sleep Quality; Study 1)

\begin{tabular}{|c|c|c|c|c|}
\hline & \multicolumn{2}{|c|}{ Negative Affect } & \multicolumn{2}{|c|}{ Tense arousal } \\
\hline & Evening & Day & Evening & Day \\
\hline & Model 5a & Model 5b & Model 6a & Model 6b \\
\hline Fixed Effects & & & & \\
\hline Intercept & $\begin{array}{l}4.019^{*} \\
(.078)\end{array}$ & $\begin{array}{l}4.009 * \\
(.077)\end{array}$ & $\begin{array}{l}4.024^{*} \\
(.077)\end{array}$ & $\begin{array}{l}4.018^{*} \\
(.076)\end{array}$ \\
\hline Study day & $\begin{array}{l}-0.011 * \\
(.004)\end{array}$ & $\begin{array}{l}-0.010^{*} \\
(.003)\end{array}$ & $\begin{array}{l}-0.011 * \\
(.004)\end{array}$ & $\begin{array}{l}-0.010^{*} \\
(.003)\end{array}$ \\
\hline School day & $\begin{array}{l}-0.125^{*} \\
(.051)\end{array}$ & $\begin{array}{l}-0.134 * \\
(.051)\end{array}$ & $\begin{array}{l}-0.130 * \\
(.052)\end{array}$ & $\begin{array}{l}-0.139 * \\
(.051)\end{array}$ \\
\hline $\begin{array}{l}\text { Within-person effect } \\
\text { Lagged negative affect / } \\
\text { tense arousal }\end{array}$ & $\begin{array}{l}-0.056^{*} \\
(.021)\end{array}$ & $\begin{array}{l}-0.071^{*} \\
(.034)\end{array}$ & $\begin{array}{l}-0.042^{*} \\
(.017)\end{array}$ & $\begin{array}{l}-0.045 \\
(.028)\end{array}$ \\
\hline $\begin{array}{l}\text { Negative affect / tense } \\
\text { arousal }\end{array}$ & $\begin{array}{l}-0.396^{*} \\
(.071)\end{array}$ & $\begin{array}{l}-0.393 * \\
(.071)\end{array}$ & $\begin{array}{l}-0.373^{*} \\
(.065)\end{array}$ & $\begin{array}{l}-0.384^{*} \\
(.064)\end{array}$ \\
\hline $\begin{array}{l}\text { Random Effects } \\
\text { (Standard Deviations) }\end{array}$ & & & & \\
\hline Intercept & 0.586 & 0.578 & 0.580 & 0.578 \\
\hline Study day & 0.029 & 0.026 & 0.028 & 0.026 \\
\hline School day & 0.228 & 0.249 & 0.228 & 0.257 \\
\hline $\begin{array}{l}\text { Lagged negative affect / } \\
\text { tense arousal }\end{array}$ & 0.065 & 0.168 & 0.064 & 0.151 \\
\hline Residual (Level 1) & 0.715 & 0.718 & 0.710 & 0.716 \\
\hline
\end{tabular}

Note. Table depicts point estimates (unstandardized coefficients; standard errors of fixed effects in parentheses). Number of observations $=1,865-2,083$; number of participants $=$ 108. Significance level for single random variances is not depicted.

$* p<.05$ 
Table 4

Results of the Dynamic Structural Equation Models.

Study 1

Autoregressive effects

Sleep quality

Time in bed

Positive affect

Negative affect

\section{Cross effects}

Sleep quality $\rightarrow$ Positive affect

Sleep quality $\rightarrow$ Negative affect

Time in bed $\rightarrow$ Positive affect

Time in bed $\rightarrow$ Negative affect

Positive affect $\rightarrow$ Sleep quality

Negative affect $\rightarrow$ Sleep quality

Positive affect $\rightarrow$ Time in bed

Negative affect $\rightarrow$ Time in bed

Random Variances

Autoregressive effects

Sleep quality

Time in bed

Positive affect

Negative affect

Cross effects

Sleep quality $\rightarrow$ Positive affect

Sleep quality $\rightarrow$ Negative affect

Time in bed $\rightarrow$ Positive affect

Time in bed $\rightarrow$ Negative affect

Positive affect $\rightarrow$ Sleep quality

Negative affect $\rightarrow$ Sleep quality

Positive affect $\rightarrow$ Time in bed

Negative affect $\rightarrow$ Time in bed

$\mathbf{R}^{2}$

Sleep quality

Time in bed

Positive affect

Negative affect
$.161[.100, .222] /$

$.160[.110, .212]$

$.114[.036, .194] /$

$.115[.046, .182]$

$.379[.304, .450] /$

$.378[.334, .419]$

$.408[.328, .479] /$

$.405[.364, .443]$

$.080[.044, .118] /$

$.099[.058, .139]$

$-.058[-.097,-.027] /$

-.073 [-.111, -.036]

$.012[-.011, .035] /$

$.023[-.013, .059]$

$.003[-.021, .026] /$

$.005[-.031, .039]$

$.108[.044, .170] /$

$.102[.052, .153]$

$-.080[-.137,-.023] /$

-.088 [-.137, -.040]

$-.008[-.072, .059] /$

$-.009[-.065, .049]$

$.018[-.043, .075] /$

$.020[-.038, .076]$
$.033[.013, .062]$

$.034[.005, .080]$

$.091[.062, .134]$

$.107[.076, .153]$

$.009[.003, .019]$

$.005[.001, .016]$

$.002[.001, .005]$

$.001[.001, .004]$

$.024[.008, .054]$

$.022[.007, .048]$

$.009[.001, .034]$

$.006[.001, .024]$

$.168[.130, .210]$

$.082[.040, .134]$

$.281[.245, .318]$

$.300[.268, .338]$

Study 2

$.192[.111, .269] /$

$.192[.123, .256]$

$.103[.013, .190] /$

$.103[.017, .185]$

$.416[.344, .485] /$

$.414[.359, .471]$

$.348[.263, .433] /$

$.344[.291, .398]$

$.113[.062, .172] /$

$.132[.082, .182]$

$-.024[-.047,-.004] /$

-.061 [-.105, -.015]

$-.016[-.048, .016] /$

$-.036[-.089, .014]$

$-.005[-.022, .012] /$

$-.018[-.072, .033]$

$.101[.012, .186] /$

$.089[.031, .150]$

$-.069[-.212, .105] /$

$-.045[-.110, .015]$

$.024[-.094, .156] /$

$.009[-.055, .078]$

$-.060[-.248, .124] /$

$-.024[-.086, .037]$

$.036[.012, .075]$

$.018[.002, .066]$

$.047[.023, .084]$

$.091[.058, .137]$

$.026[.007, .053]$

$.002[.001, .006]$

$.004[.001, .012]$

$.001[.001, .003]$

$.048[.013, .110]$

$.100[.008, .306]$

$.065[.009, .192]$

$.129[.027, .397]$

$.187[.138, .239]$

$.114[.065, .171]$

$.324[.272, .380]$

$.269[.225, .320]$ 
Note. Table depicts unstandardized / standardized effects and their associated $95 \%$ credible interval. Fixed effects whose $95 \%$ credible interval does not contain zero are highlighted in bold.

$N=108($ Study 1$) ; N=84($ Study 2$)$. 
Table 5

Descriptive Statistics Study 2

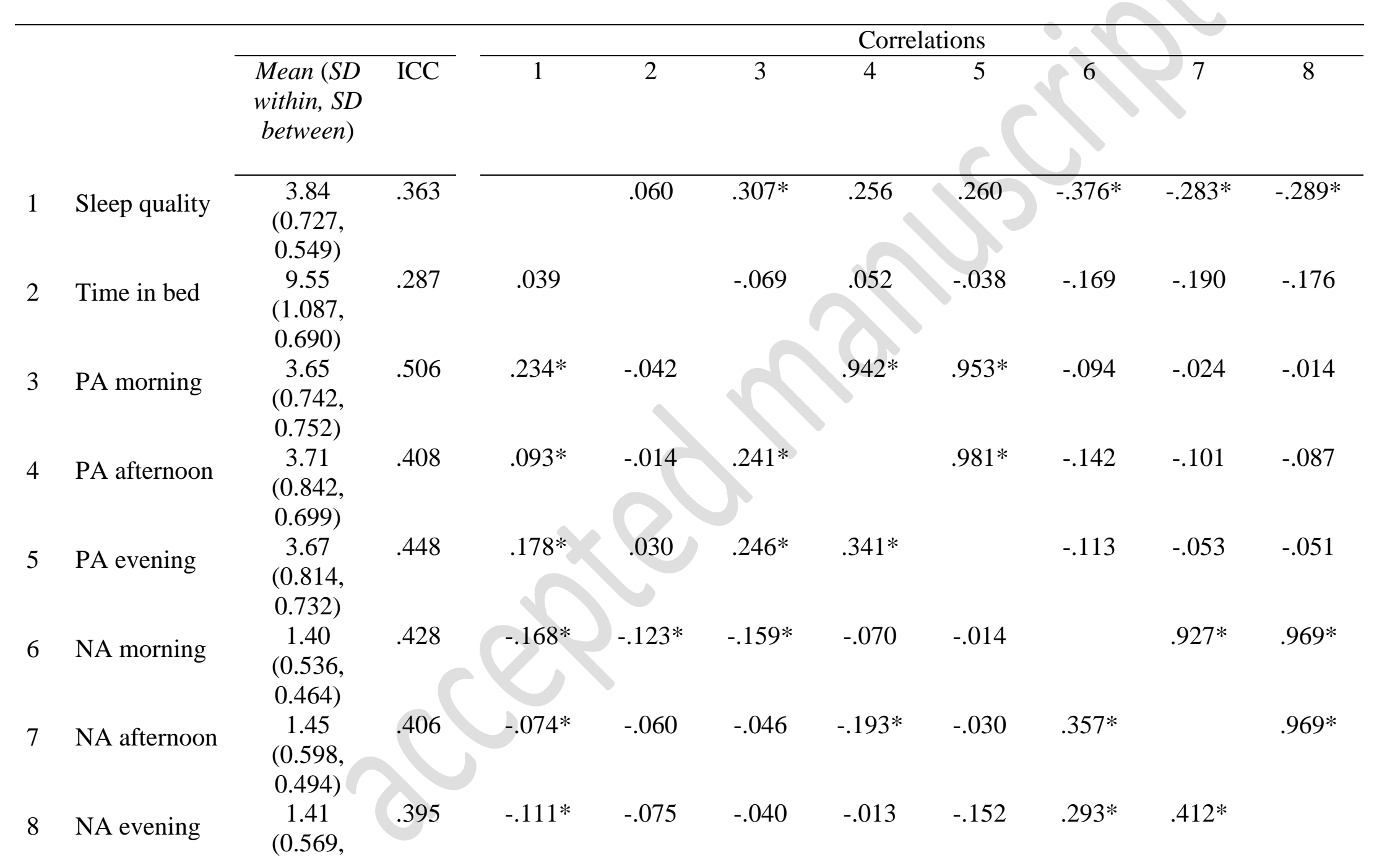


0.459)

Note. Table depicts descriptive statistics. Correlations in the upper diagonal refer to the between-person level; correlations in the lower diagonal refer to the within-person level. ICC = intra-class correlation; PA = positive affect; NA = negative affect.

${ }^{*} p<.05 . N=84$ 
Table 6

Summary of the Results for the Preregistered Hypotheses.

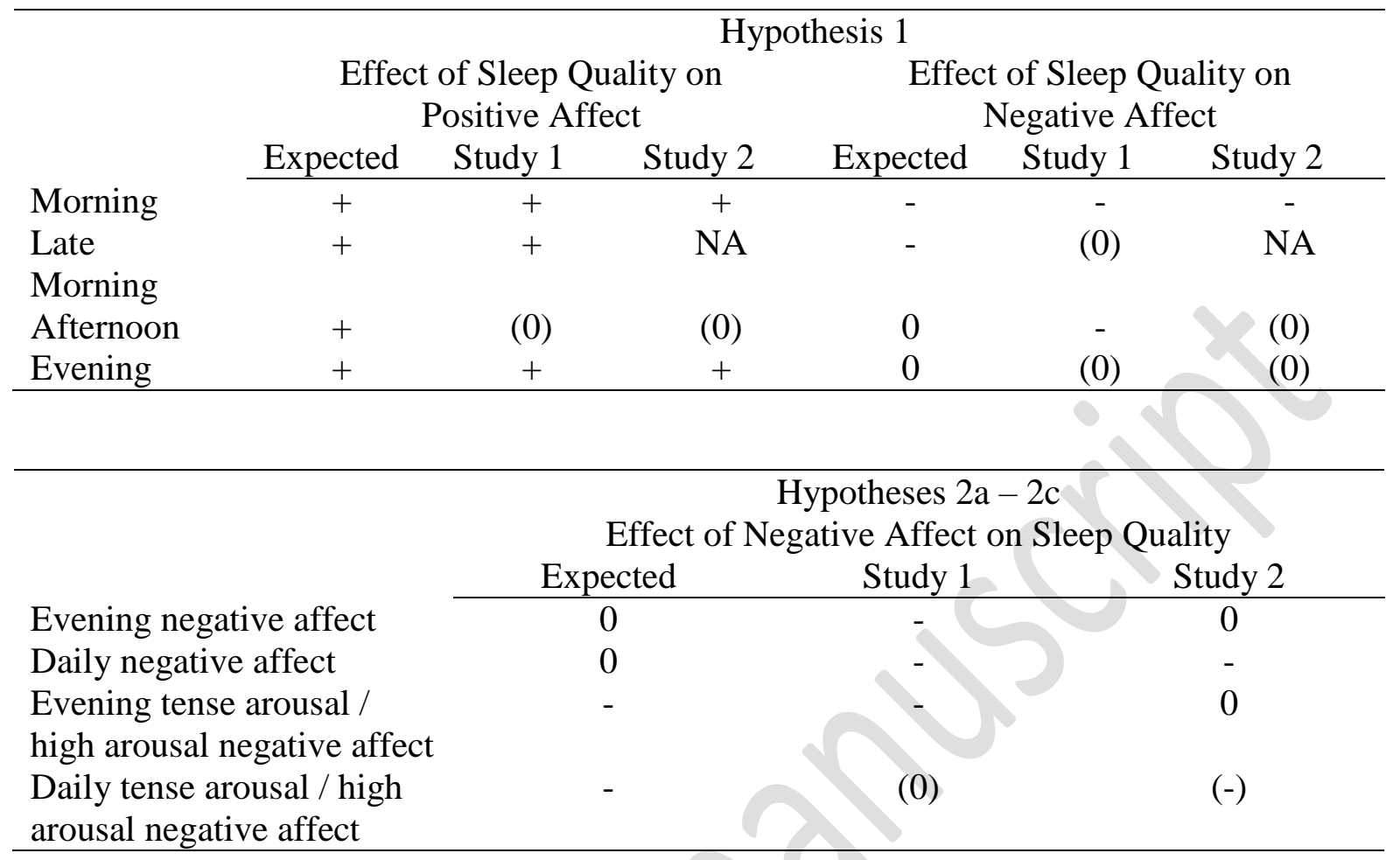

Note. Table summarizes the findings for the preregistered hypotheses. + : positive association; -: negative association; 0: no (statistically meaningful) association; NA: not included. Results in parentheses indicate that the results were not consistent across all sensitivity analyses. 


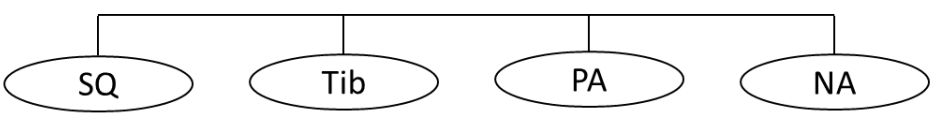

between

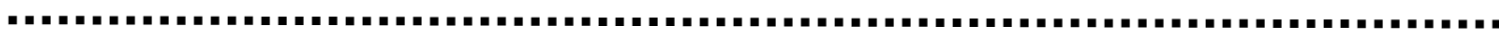

within

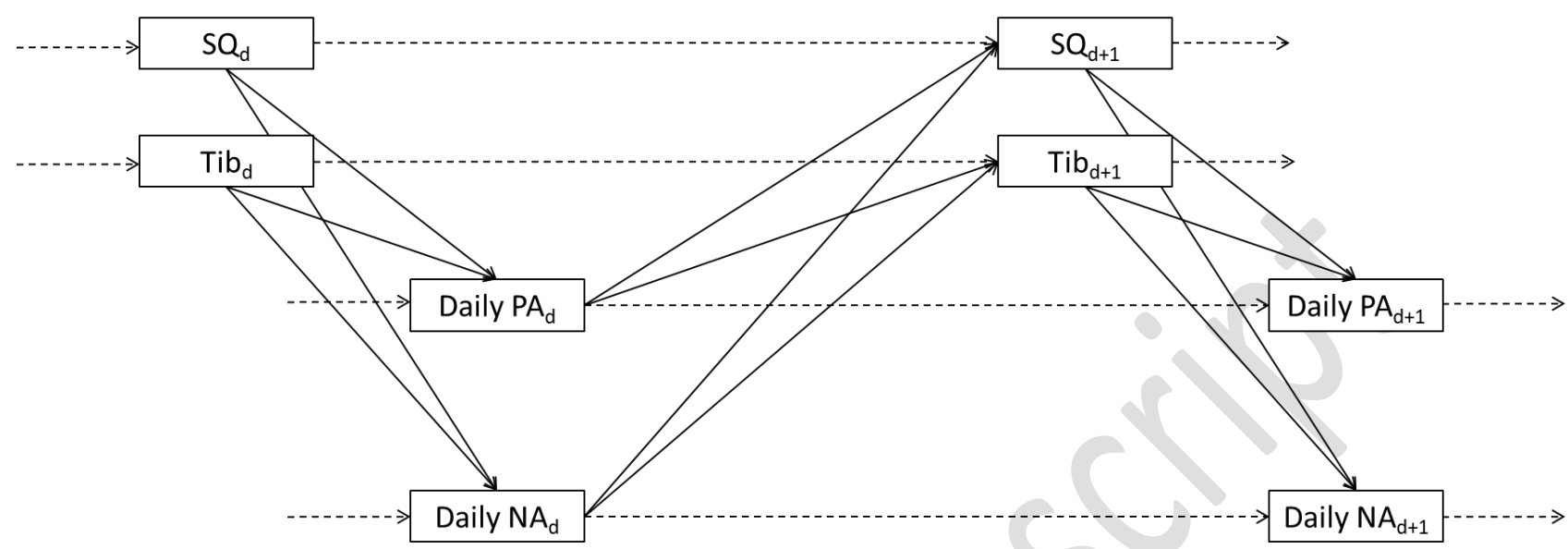

Figure 1. Schematic representation of the DSEM tested. All regression coefficients on the within-person level were estimated as random slopes. Additionally, random effects for the innovation variances of all four variables were estimated. $S Q=$ sleep quality; Tib = time in bed; $\mathrm{PA}=$ positive affect NA = negative affect. 